Reviews in Digital Humanities • Vol. 2, No. 6

\title{
Review: Against All Odds
}

Kimber Thomas ${ }^{1}$

${ }^{1}$ University of North Carolina, Chapel Hill

Published on: Jun 14, 2021

DOI: $10.21428 / 3 \mathrm{e} 88 \mathrm{f} 64 \mathrm{f} . \mathrm{aec} 6 \mathrm{c} 6 \mathrm{fO}$

License: Creative Commons Attribution 4.0 International License (C-BY 4.0). 


\section{Project}

Against All Odds: The First Black Legislators in Mississippi

\section{Project Director}

DeeDee Baldwin, Mississippi State University

Project URL

https://much-ado.net/legislators/

\section{Project Reviewer}

Kimber Thomas, University of North Carolina, Chapel Hill

\section{Project Overview}

\section{DeeDee Baldwin}

Against All Odds (AAO) facilitates research on over 150 African American men who served in the Mississippi state legislature from Reconstruction (1863) until the 1890s. It provides biographical information, portraits, quotes from primary and secondary sources, newspaper clippings, and other documents for each individual, including census records and Mississippi House and Senate journals. The project began in 2018 as an act of archival reparations to address the lack of documentation and difficulty of undertaking research on these legislators. Archival reparations, as defined by Anna Robinson-Sweet in The American Archivist, are proactive efforts by archivists to restore people of color to the very white-centered archival and historical record. $\underline{1}$ With that as the philosophical impetus, AAO is a digital archive that devotes attention to these African American leaders.

The site was created with two audiences in mind: historical researchers (from K-12 to professional historians) and genealogical researchers. For historical researchers, basic biographies and primary source documents are meant to serve as a short introduction to each subject and to be a springboard to more in-depth research. For genealogists, legislators' family information is provided where available to help descendants find their ancestors; this is published both on the AAO site as well as a family tree on Ancestry.com. One descendant of Wilson Hicks noted the impact of the site: "I had no idea, and I feel quite proud now thanks to you." 
The site, hosted by Dreamhost, is built in WordPress with a page for each legislator. In November of 2020, the original website was mirrored as an Omeka digital exhibit on the Mississippi State University Libraries website. Going forward, both iterations will be maintained with the same content. AAO was the subject of a presentation for the Mississippi Department of Archives and History's weekly “History is Lunch" program held at the Mississippi Civil Rights Museum on September 9, 2020. The project was also presented as part of Humanities Commons' first Twitter conference on July 18, 2019. "Finding Isom Stewart," a 2018 presentation at Black Communities: A Conference for Collaboration in Durham, NC, introduced attendees to the Noxubee County legislator who inspired the project.

The creator, researcher, and maintainer of the website is DeeDee Baldwin, who serves as the History Research Librarian in the Research Services Department at Mississippi State University Libraries. Before accepting that position in 2017, Baldwin worked for ten years in the library's Manuscripts Department, processing collections and creating metadata for the archive's digital collections. She is a past president of the Society of Mississippi Archivists and a member of the African American Intellectual History Society, the Mississippi Historical Society, the National Genealogical Society, and the Association for Computers and Humanities.

\section{Project Review}

\section{Kimber Thomas}

In the summer of 1870, Frederick Douglass wrote a letter to Louis Prang, a Bostonbased printer, commenting on a chromolithograph that Prang's company had recently produced of Hiram Rhodes Revels, the first African American U.S. Senator to represent Mississippi during Reconstruction. "Whatever may be the prejudices of those who may look upon it," Douglass wrote of the photograph, "they will be compelled to admit that the Mississippi Senator is a man, and who will easily pass for a man among men." Douglass used the portrait of Revels as a reference point to mark and affirm Black humanity and citizenship at a time when it was being devalued and to honor a Black man who had moved into a position of public leadership and who sought, through legislation, to restore the economic, civil, and political rights of formerly enslaved people. Against All Odds: The First Black Legislators in Mississippi (AAO) does similar work as a digital archive of the African Americans elected to Mississippi's state legislature from Reconstruction through the 1890s. The project collects content about and facilitates historical and genealogical research on the Black legislators who were 
at the center of conversations about race, citizenship, and democracy in Mississippi after the Civil War.

Built using WordPress, the website allows users to view each legislator by county, date, and name. There is a well-constructed and easily navigable page for each legislator, where users can view the legislator's portrait, where available, and explore relevant details such as their years served in the state senate, biographical information gathered from census records, and quotes from primary and secondary sources. When viewing legislators by county, users encounter a static map that would benefit from being made interactive; such an addition might make navigation even easier and may provide an opportunity to supplement existing information with new types of data. The pages also include transcribed newspaper clippings, links to extensive biographies for more well-known legislators, as well as recommended sources for further reading. While the project director notes that some of the primary sources use racist language, future work might include adding transcripts or audio clips of the legislators' speeches or sermons to the entries, where available, as a way to balance the narrative and to demonstrate the level of discourse that took place during Reconstruction.

Nevertheless, these entries-which provide documentation about the forgotten African American legislators who represented the metaphorical triumph of Reconstruction in the U.S.-are multimodal texts that underscore the relevance of this project as a work of "archival reparations."

AAO expands our understanding of Mississippi's first Black legislators by providing information about those who are lesser known and understudied. As such, AAO has great promise for advancing scholarship on African American history in Mississippi. The project also cross-posts pertinent information about legislators into genealogy sites, demonstrating its potential for engaging audiences both inside and outside academia and showing the ways a digital archive might be used in historical and genealogical research on African Americans. At a time when historians and scholars of Black history and culture are critically examining the period of Reconstruction, both as a precedent for our current historical moment and for its role in birthing white supremacy in America, AAO offers an invaluable digital resource for exploring questions of race, citizenship, equality, and democracy in Mississippi and beyond.

\section{Footnotes}

1. Anna Robinson-Sweet, "Truth and Reconciliation: Archivists as Reparations Activists," The American Archivist 81.1 (2018): 23-37. doi:

https://doi.org/10.17723/0360-9081-81.1.23 